Accepted for publication in "Current Alzheimer Research"

Note: This is an uncorrected version of an author's manuscript accepted for publication. Copyediting, typesetting, and review of the resulting proofs will be undertaken on this manuscript before final publication. During production and prepress, errors may be discovered that could affect the content.

\title{
The cognitive effects of wearable cameras in Mild Alzheimer disease - An experimental study
}

Ana Rita Silva

Faculty of Psychology and Educational Sciences, University of Coimbra

\section{Maria Salomé Pinho}

Faculty of Psychology and Educational sciences, University of Coimbra

Luís Macedo

Center for Information Systems, University of Coimbra

Christopher J.A. Moulin

Laboratoire de Psychologie \& NeuroCognition (CNRS UMR 5105), Université

Grenoble Alpes

Corresponding author

Ana Rita Silva

Faculty of Psychology and Educational Sciences of the University of Coimbra CINEICC - Cognitive and Behavioural Center for Research and Intervention Colégio Novo Street, s/n

3001-802 Coimbra

PORTUGAL

+351239851450

ana.rita.ess@gmail.com 


\section{THE COGNITIVE EFFECTS OF WEARABLE CAMERAS ON MEMORY}

Abstract

Background. Wearable cameras are a new type of intervention aimed at stimulating memory in Alzheimer's disease (AD). Such passive external memory aids have started to be considered as alternatives to both more active external aids (such as writing in diaries, journals, and timetables) and to internal cognitive strategies (such as spaced retrieval, errorless learning). Objective. In order to understand the benefits of these innovative devices for memory compensation, the present experiment examined the effectiveness of two memory training strategies: SenseCam, a wearable camera, a passive external memory aid and a memory training programme (MEMO+) created from tasks known to stimulate memory, in comparison with a control condition, a personal written diary. Method. Fifty-one patients with mild AD were randomly assigned to one of these three groups. Training lasted for six consecutive weeks, two sessions a week, one hour each, for all groups. Patients underwent a neuropsychological assessment at baseline, after treatment and at follow up (six months later). Results. Groups showed non-significant differences at baseline. After treatment and at follow up, the SenseCam group had a superior autobiographical memory (AM) performance, compared to the Memo+ and Diary groups. The SenseCam and the Memo+ groups both showed improved episodic and semantic memory, and somewhat improved executive function. Conclusion. Our results suggest that passive memory training with SenseCam is a promising alternative to traditional memory training programs to help AD patients with autobiographical memory performance.

Keywords: Alzheimer's disease; memory; cognitive training; wearable cameras; nonpharmacological interventions; SenseCam 


\section{THE COGNITIVE EFFECTS OF WEARABLE CAMERAS ON MEMORY}

\section{Introduction}

The development of wearable cameras has brought new possibilities to the field of memory rehabilitation [for a review see 1]. SenseCam, originally built with the purpose of being a "retrospective memory aid" [2] has been shown to support memory-impaired populations' ability to remember personal events. This camera automatically takes pictures from the wearer's point of view, without his/her intervention, requiring no active encoding of the to-be-remembered information. The still images are later reviewed as a sequence like a movie using a personal computer. The initial findings are that SenseCam images effectively cue the retrieval of information depicted in the images even after intervals as long as eleven months $[3,4]$. To date, however, there has been relatively little evaluation of the benefits of SenseCam in Alzheimer's disease (AD), and no experimental examination of the generalized benefits of SenseCam review on measures of neuropsychological function in $\mathrm{AD}$. The existing studies in $\mathrm{AD}$ have mostly been conducted as proof of concept by computer scientists interested in the application of new technology or have relied on very small samples without control comparisons.

Initial findings suggest that SenseCam can stimulate memory more generally. For example, Hodges and colleagues [2] suggested that seeing SenseCam images allowed people to remember information not depicted in the images, the retrieval of 'something more' [1]. In support, an experiment using a battery of neuropsychological assessment measures revealed that reviewing SenseCam images improved healthy young and older adult test scores for measures not related to the content of the SenseCam images [5]. In particular, this finding was clearest for autobiographical memory. Using a standardized autobiographical memory assessment measure (the Autobiographical Memory Test, AMT) [6] and a within subject design, SenseCam showed a large effect $\left(\eta^{2} p=.82\right)$ compared to a written diary control condition. This meant that there was an improvement in memory for autobiographical events from across the lifespan, not just the contents of the reviewed images.

This has been interpreted as showing that SenseCam review mimics autobiographical memory (first person point of view, visual information, structured in brief time slices, reviewed in a temporal order). As such, SenseCam review could be proposed to stimulate networks of neurones involved in memory retrieval, which is clearly of interest to those 


\section{THE COGNITIVE EFFECTS OF WEARABLE CAMERAS ON MEMORY}

wishing to rehabilitate memory function in Alzheimer's disease. This stimulation hypothesis predicts that SenseCam review should lead to generalised benefits not just for the retrieval of information depicted in the images, through the activation of otherwise impoverished neural structures. Critically, this hypothesis receives support from neuroimaging studies that show that SenseCam review in healthy groups leads to activations in the hippocampus and temporal lobe more generally $[7,8]$.

Previous studies have focussed on the cognitive effects of SenseCam with regards to autobiographical memory performance. However, as we proposed in our review [1] the patterns of neural activation that are triggered by SenseCam review, while strengthening autobiographical memory traces, also recruit attention and executive control processes, as described by Conway's Self Memory System [9]. Thus, one might expect SenseCam use to ameliorate performance in these cognitive domains activated by a broader autobiographical memory network. In support, Berry et al. [3] concluded, in their case study, that their patient was able to organise her executive strategies more effectively by using SenseCam for some period of time. Perhaps more critically, neuroanatomical reviews of autobiographical memory function have implicated a large network which relies on executive function (10), and clinical studies of memory impairment have shown a relationship between proficient executive functions and autobiographical memory retrieval $(11 ; 12)$.

Specifically in $\mathrm{AD}$, there is an inability to travel mentally back in time and bring to consciousness past events; episodic memory is compromised even in the mild stages of this disease $[13,14]$. As such, both anterograde and retrograde memory are impaired, with difficulties in encoding and retrieving recent experiences and deficits in retrieving specific autobiographical memories (AM) from earlier in life. Thus, in AD we see disproportionate deficits in Autobiographical Memory (AM), but in turn it is this type of memory which seems to benefit most from rehabilitation using SenseCam, at least so far in healthy groups [5]. Importantly, the intimate relationship between AM and identity [15] pinpoints the highly disruptive effects of the impairment of this type of memory domain in mild AD can have on patients' quality of life. The progressive decline in memories that built the person's self-concept will influence well-being. Despite being one of the areas of cognition most critical for autonomy and well-being, autobiographical memory is difficult to treat or rehabilitate due to its personal and subjective nature, but 


\section{THE COGNITIVE EFFECTS OF WEARABLE CAMERAS ON MEMORY}

technological innovations such as SenseCam, can now re-present people with personally-relevant materials in a way that was not otherwise possible.

To put SenseCam research into a theoretical context, non-pharmacological interventions in $\mathrm{AD}$ began as the application of intensive memory-based interventions that required substantial cognitive effort and drew heavily on episodic memory [16, 17] The weak efficacy and lack of generalization effects produced by this approach contributed to the rise of another category of interventions, driven by technological advances; the use of external memory aids or "memory prosthetics" [18]. These techniques are commonly used in memory-impaired patients with treatable and non-progressive conditions [19], and they have started to be tested with people with AD more recently. For episodic memory, compensatory strategies are considered more effective than restitution oriented strategies [20,21]. Moreover, rehabilitation techniques which are 'passive' are likely to be more effective and rewarding than active techniques, such as memory training, which are intensive and cognitively demanding [1].

Thus far, to our knowledge, there are only three published studies using SenseCam as a memory aid for patients with Alzheimer disease. Lee and Dey [22] tested three patients with mild AD. These patients wore the SenseCam for two weeks but only for personally significant events (as considered by the patient or its caregiver). The use of the camera by the patient increased the recall of details of the events compared to the used of the camera by his caregiver or no treatment. Crete-Nishiatha et al. [23] tested SenseCam usage during three outings in five patients with $\mathrm{AD}$. It was used an adapted autobiographical interview, and these patients again showed an increase in recall of the events depicted by the SenseCam images. Finally, Woodberry et al. [24] tested the efficacy of SenseCam to improve recall of information about personally significant events in six patients with mild $\mathrm{AD}$, compared to the effects of a personal Diary intervention (writing in the diary the interesting events of the day), in a within subjects' design. Patients wore the SenseCam, again only for personally relevant events, over a threemonth period. Five of the six participants recalled more details from the SenseCam-cued events compared to the Diary condition. This effect remained at three-month follow up. These results suggest that SenseCam is helpful in AD population, and can stimulate recall of specific autobiographical memories depicted in the images. However, it is unknown 


\section{THE COGNITIVE EFFECTS OF WEARABLE CAMERAS ON MEMORY}

if this effect is generalizable to global autobiographical memory function, and indeed to other memory domains.

In the present experiment, we examined the efficacy of SenseCam to stimulate cognition in a relatively large group of patients with mild $\mathrm{AD}$. One previous study with a healthy population has tested global cognitive effects of SenseCam [5]. Using this as basis, we tested a sample of mild AD patients on a similar set of standardized measures with an emphasis on the improvement of AM. We also examined other relevant cognitive domains (tests of episodic memory, semantic memory, attention and executive function) [25]. To date, SenseCam studies in AD have used no-aid/no-treatment conditions [22] or a personal written diary [24] as control conditions. To control for neuropsychologistpatient contact and the review or discussion of daily events, we chose a diary control condition. Previous research has shown such interventions to be ineffective for most AD patients, even in the mild stages, due to some constraints (the need to remember to fill the entries and to remember the past events in order to correctly fill the diary) [19]. Additionally, to examine in depth the value of SenseCam, one should compare its effects to interventions that are expected to be efficacious for this purpose. To this end, a memory training programme - Memo+ (see Methods section for a detailed description), was constructed based upon the most recent advances in terms of internal strategies effective for AD patients' memory functioning, such as errorless learning, spaced retrieval and mnemonic training. SenseCam was compared with this memory-training programme and we aimed to consider the differences between a compensatory passive approach and a restorative active approach intervention.

\section{Method}

\section{Participants and Design}

Fifty-one patients with mild AD took part in this study (aged 62 to 80 years, $M=73.65$, $S D=5.498$ ). They were recruited from the Psychiatric and Neurology services of Coimbra University Hospital (CHUC), at the Portuguese Alzheimer's Disease Association (APFADA) and at the Residential Care Facility at Rainha Santa Isabel. Diagnoses were provided by independent neurologists and psychiatrists (specialized in geronto-psychiatry) responsible for each service. Participants met the following criteria: a diagnosis of probable AD (according to the NIA-AA workgroup criteria) [26]; diagnosis 


\section{THE COGNITIVE EFFECTS OF WEARABLE CAMERAS ON MEMORY}

established within the past six months; community-dwelling or integrated into a day care centre; and cared for by a well-identified caregiver willing to participate in the study; score between 15 and 26 on the Mini-Mental State Examination (MMSE) [27]; absence of severe symptoms of depression (according to the score on the Geriatric Depression Scale (GDS) [28]; and dementia severity between very mild (0.5) and mild (1.0), according to the Clinical Dementia Rating (CDR) [29]. The study procedures were approved by the research ethics board of the Hospital Centre of the University of Coimbra (CHUC) (ethics approval number 4212). All participants provided informed consent.

After screening, participants that met the criteria for the study were randomly assigned to one of three groups of cognitive training (See Figure 1 for the study protocol). Randomization was performed in the following way: as we aimed for a sample of sixty participants (twenty in each condition), we randomized (at random.org) numbers from 1 to 60 before the study took place. The first twenty randomized numbers were assigned to the Memo+ condition, the second twenty randomized numbers were assigned to the SenseCam condition and the third twenty randomized numbers were assigned to the Diary condition. As participants met the criteria for the study and after screening, each participant was assigned consecutively one of the randomised numbers, such that they were allocated to one of the three groups in a pre-determined random order.

One-way ANOVAs demonstrated no significant difference between groups for age, $F(2$, $48)=1.475, p=.241$, level of education (years of formal education, $F(2,48)=2.340, p$ $=.109$, with a total of $73.1 \%$ of participants that completed primary school, $21.2 \%$ that finished high school and 3,8\% that finished superior studies, without between group differences for these educational levels; $\mathrm{X}^{2}=19.40, \mathrm{p}=.09$ ), or estimated premorbid IQ on the Portuguese version of the National Adult Reading test (TELPI - Teste de Leitura de Palavras) [30], $F<1$. The groups did not differ on general cognitive status according to the Addenbrooke's Cognitive Examination (ACE-R) [31], $F<1$ at baseline. The length of the cognitive training programmes was six weeks, and there were two post-intervention assessment visits: one immediately after the end of the rehabilitation sessions and a sixmonth follow up. Only 46 patients took part in the third assessment (dropouts were due to the following reasons: two participants died during the follow-up interval and three participants changed address, missing the third visit). 


\section{THE COGNITIVE EFFECTS OF WEARABLE CAMERAS ON MEMORY}

\section{INSERT FIGURE 1 ABOUT HERE}

\section{Cognitive training interventions}

We compared three different interventions: a wearable camera (SenseCam group), a. memory training programme with paper and pencil exercises (Memo+ Group) and a personal written diary (Diary Group). The number of sessions for each type of intervention was the same (eleven sessions, twice a week, one hour per session).

SenseCam Group. In this memory training group, SenseCam was used to capture images from participants' daily life for the whole period of the intervention (six weeks). The review sessions occurred twice a week (with a face-to-face meeting with the experimenter, as for the other conditions). In the three-day interval between each session, participants wore the camera every day for the longest possible time in order to maximize the potential of the device and the number of images gathered (they were also informed that they could remove or turn off the camera for any events they wanted to remain private). All the images gathered in those three-days were reviewed during the following session. Approximately 7000 images were shown to the participants on a computer. This sequence of collecting images during three days of SenseCam usage and reviewing the full set of images in a one-hour session was repeated for the eleven-sessions in the intervention. During these sessions participants reviewed the images and were asked to comment on what they were watching, but the experimenter did not give feedback on the accuracy of those comments. Patients and their caregivers were instructed, before starting to use the device, on how to charge it and how to use the buttons (privacy, on/off button, manual trigger).

Memo+ Group. This programme of cognitive training included a set of paper and pencil exercises to stimulate cognition. It was developed based on recent advances in memory training of people with $\mathrm{AD}$. We selected tasks and techniques where there was published evidence of memory improvement in brain injury. In short, we included training and practice in the following domains: exercises to improve motivation [32], attention [33], working memory [34], autobiographical and episodic memory [35, 36, 37, 38] semantic memory [39] and implicit memory [40]. An adapted motivational interview was constructed for the start of the sessions [32] (that included a set of open questions regarding the actual interest of the participants in taking part in the study, expectations 


\section{THE COGNITIVE EFFECTS OF WEARABLE CAMERAS ON MEMORY}

about possible gains to be obtained in the study, and also questions regarding the prior existence of self-initiated activities to stimulate the brain - such as crosswords, Sudoku, reading, etc.) and some psychoeducation was given at the first session about neurodegenerative diseases and the content of the cognitive training sessions. These sessions involved the practice of cognitive strategies for learning and retention of information (spaced retrieval, vanishing cues, errorless learning, mnemonics). Exercises had progressive levels of difficulty throughout the training sessions. Each session featured two exercises of explicit memory (e.g. retain a shopping list with an increasing number of items, from five to seven, and recall them using the spaced retrieval technique, e.g., recall after one minute, three minutes, five minutes to a maximum 12-minute interval) and one exercise of implicit memory (e.g. read a set of instructions and perform the actions depicted in those instructions, e.g., make a call to someone from a list of contacts). At the end of each session, feedback from the neuropsychologist (ARS) was given concerning the performance of the participant on each exercise.

Personal Diary Group (Control Condition). In this intervention group, participants were asked to write down their daily activities in a personal journal with sections to fill in and to then read it to the experimenter in each session. The diary was organized into sections on a one-page-per-day basis. These sections were provided to participants in the knowledge that AD patients have difficulty in free recall of events without cues to help them, and the sections were thus chosen to act as cues for remembering [41]. Sections were the following: Event description (where the participant writes the activity done in that day, for example, "I had breakfast with my wife"); Time (where the participant had to register the time of the day the event took place, for example, "7.30 a.m."); place (to fill with information about where the event took place, for example, “in my kitchen”); people involved (where the participant had to describe other people that were part of the event described, for example, "my wife Maria"); and emotional description (where the participant was asked to described how they felt during the event, for example, "calm”). Two other sections were also included as aids for prospective memory: Appointments and Other Notes. The participant was instructed to fill the diary pages at the end of each day, and carers were instructed to remind the participant to complete the diary.

\section{Neuropsychological evaluation}




\section{THE COGNITIVE EFFECTS OF WEARABLE CAMERAS ON MEMORY}

A comprehensive battery of neuropsychological tests was applied at three time points: 1) baseline (before randomly assigning participants to each cognitive intervention); 2) after intervention (the week after the six-weeks intervention ended); 3) follow-up (approximately six months after the end of the intervention). The full set of instruments described in Table 1 was given to all groups, and at each of the three visits. Parallel forms exist in Portuguese for few of the tests; so the same version of each task was readministered.

\section{INSERT TABLE 1 ABOUT HERE}

\section{Statistics}

Analyses for this study were conducted using the Statistical Package for Social Sciences 22.0 (SPSS 22.0; IBM SPSS, Chicago, IL).

For the definition of the sample size, a power analysis was performed and based on the previously reported effects in Silva et al. [5] which used the same measure of autobiographical memory, but in a non-dementing sample and in a within-subject design. For the SenseCam condition, the (abridged) AMT score was 19.07 and the diary condition was 12.57; representing an effect of 1.5 - whereby the SenseCam condition was approximately 1.5 times the performance of the diary condition. We thus expected a similar effect size in the Alzheimer's group. However, the Alzheimer's disease group was likely to have a different baseline performance and a larger variability. As such, we took the mean and standard deviation from Moses et al. [47] which were 17.02 (mean) and 6.20 (standard deviation) as a baseline for a mild AD sample. These values yielded a sample size of 9 in each group with an estimated power of .80 and an alpha value of .05 . The aim, however, given practical considerations and typical recruitment of patients at the collaborating institutions, was to have 20 patients in each of the three groups.

Data were examined and no outliers were identified. The distributions of data were examined using histograms, plots, and tests of skewness and kurtosis. All demographic characteristics and outcome measures followed normal distributions. Differences in the demographic characteristics between the groups were analysed using one-way ANOVAs. We also performed one-way ANOVAs to examine the differences between groups in the outcome measures at baseline, and the impact of cognitive training in those measures was analysed using $3 \times 3$ mixed design ANOVAs (with Group as the between subject factor 


\section{THE COGNITIVE EFFECTS OF WEARABLE CAMERAS ON MEMORY}

and Visit as the within subject variable). Main effects for the between subject's variables were analysed using post-hoc Fisher LSD statistics and other significant main effects and interactions for the within subjects variables were analysed using pairwise comparisons. Within these sub-analyses we used Bonferroni's adjustment for multiple comparisons. The $\alpha$ value was set at .05 for all statistical tests. Differences in each training group performance in the outcome measures between baseline (Visit 1), immediately after training (Visit 2) and six months' follow-up (Visit 3) were analysed using paired samples t-tests. Setting the $\alpha$ for the study involved consideration of the fact that multiple comparisons were used on the same data in this study, which would generally lead to using a more conservative $\alpha$ to avoid Type I errors. However, the study also involved exploration of a new cognitive training intervention with a relatively small clinical sample. This meant that it was equally important to avoid Type II errors, possibly missing information about the potential effectiveness of the program. Therefore, for each separate analysis of the different dependent variables, no statistical adjustment was made for the multiple comparisons.

\section{Results}

\subsection{Participant characteristics}

The groups to which the participants were assigned in this study were randomized and showed no significant differences on sociodemographic variables, as well as for general cognitive function and depressive symptoms. Table 2 describes the characteristics of the sample at baseline.

\section{INSERT TABLE 2 ABOUT HERE}

\subsection{Neuropsychological assessment}

Our strategy for analysis was to use mixed 3 x 3 ANOVAs with Group (SenseCam versus Memo+ versus Diary) as a between subjects' factor and Visit (Baseline, After cognitive training and at Follow-up) as a repeated measures factor. Since there were 46 patients at follow up, this means that our principal analyses were conducted on 46 patients. Where indicated we carried out group comparisons using Bonferroni corrected Fisher's LSD comparisons and paired sample t-tests. 


\section{THE COGNITIVE EFFECTS OF WEARABLE CAMERAS ON MEMORY}

One-way ANOVAs were performed before the mixed 3x3 ANOVAS to compare the groups' scores at baseline. The variables where groups differed at baseline were the following: World List learning, $F(2,48)=2.78, \mathrm{p}=.06$, World List recognition, $\mathrm{F}(2,48)=3.20, \mathrm{p}=.05$; Digit span global score, $\mathrm{F}(2,48)=2.95, \mathrm{p}=.06$; and Semantic global score, $\mathrm{F}(2,48)=4.69, \mathrm{p}<.001$. For these variables, despite the marginal values of significance (.06, when we use the convention of .05) we did not carry further analyses, in order to avoid Type 1 error due to baseline differences. Because of previous studies in this domain, and indeed the design of the SenseCam, we had a particular focus on autobiographical memory function, and we analyse this domain before considering the remaining neuropsychological instruments' results in detail.

\subsubsection{Autobiographical memory (AMT) [6]}

As our primary outcome, we examined the global score in this instrument (obtained by the multiplication of the number of memories recalled after the 15 keywords given and the specificity of those recalled memories). For this global score, a weak to moderate main effect of Group was found, $F(2,43)=3.94, p=.02, \eta^{2} \mathrm{p}=.16$, and Fisher LSD posthoc comparisons revealed that scores were higher for the SenseCam group in comparison to both the Memo+ group $(\mathrm{p}=.05)$ and the Diary group $(\mathrm{p}=.01)$. A moderate main effect was also found for Visit, $F(3,43)=22.94, \mathrm{p}<.001, \eta^{2} \mathrm{p}=.35$, and LSD pairwise comparisons with Bonferroni adjustment showed higher results in Visit 2 compared to both Visit $1(\mathrm{p}<.001)$ and Visit $3(\mathrm{p}=.023)$, and higher results in Visit 3 compared to Visit 1 (p<.001). Finally, an interaction effect was found for Group X Visit, $F(3,43)=16.81$, $\mathrm{p}<.001, \eta^{2} \mathrm{p}=.44$, with moderate strength. The interaction arises because whereas the SenseCam group improves between the first two visits and maintains this improvement for the third, the Dairy group shows no improvement at all, and the Memo+ group shows some improvement but this is not retained for the follow up visit (see Graph 1). That is, the SenseCam group's AM performance improved at Visit $2(\mathrm{M}=24.80, \mathrm{SD}=7.01)$ compared to Visit $1(\mathrm{M}=15.77, \mathrm{SD}=4.25, t(16)=8.32, \mathrm{p}<.001)$ and Visit 2 scores remained at about the same level for Visit $3(\mathrm{M}=24.20, \mathrm{SD}=6.21, t(14)=-1.45, \mathrm{p}=.17)$. The Memo+ group performance also improved at Visit $2(\mathrm{M}=21.25, \mathrm{SD}=4.95)$ compared to Visit 1 $(\mathrm{M}=16.49, \mathrm{SD}=2.72,(t(16)=4.11, \mathrm{p}<.001)$, but decreased at Visit $3(\mathrm{M}=17.69, \mathrm{SD}=4.37)$, with no differences between visits 1 and $3,(t(14)=1.78, p=.09)$. The Diary group performance maintained stable over the three time points of assessment, revealing the absence of an effect of training in this group (Visit $1 \mathrm{M}=17.80, \mathrm{SD}=5.39$; Visit 2, 


\section{THE COGNITIVE EFFECTS OF WEARABLE CAMERAS ON MEMORY}

$\mathrm{M}=16.53, \mathrm{SD}=5.35$; Visit $3, \mathrm{M}=16.53, \mathrm{SD}=5.93, p=55 ., \mathrm{p}=.67, \mathrm{p}=.43$, for all pairs respectively).

\section{INSERT FIGURE 2 ABOUT HERE}

As this instrument examined both the number of memories recalled and the specificity of those memories, we analysed in depth the level of specificity of the memories recalled by the patients in each group. Memories collected with the AMT can be rated as a semantic association, a categorical memory, an extended general memory; or a specific memory. As the level of specificity is associated with the quality of AM performance (specific memories are rated with 3 points, the maximum score possible), we analysed the total of memories rated as specific in each intervention group. As for the global score, a weak to moderate main effect for Group was found for specific memories, $F(2,43)=6.41, p<.001$, $\eta^{2} \mathrm{p}=.23$, and Fisher LSD post-hoc comparisons indicated that the number of specific memories retrieved by participants in the SenseCam group was higher than the Memo+ group $(\mathrm{p}<.001)$ and the Diary group $(\mathrm{p}<.001)$. A moderate main effect was again found for Visit, $F(3,43)=33.44, \mathrm{p}<.001, \eta^{2} \mathrm{p}=.43$, and performing LSD pairwise comparisons with Bonferroni adjustment revealed that in Visit 2 more specific memories were produced in comparison with Visit $1(\mathrm{p}<.001)$ and Visit $3(\mathrm{p}<.001)$, but a higher number of memories with greater specificity were retrieved at Visit 3 compared to Visit 1 $(\mathrm{p}<.001)$. A moderate interaction of Group and Visit was also found for the retrieval of specific memories, $\mathrm{F}(3,43)=16.31, \mathrm{p}<.001, \mathrm{\eta}_{\mathrm{p}}^{2}=.43$. The analysis of the means and additional paired-sample $t$ tests indicated that the SenseCam group's specificity increased at Visit 2 (Visit $1 \mathrm{M}=1.33, \mathrm{SD}=1.01$; Visit $2 \mathrm{M}=4.73, \mathrm{SD}=2.78, t(16)=5.91, \mathrm{p}<.001$ ) and was maintained at Visit 3, with no differences between these two visits $(M=4.67$, $\mathrm{SD}=2.74, t(14)=1.00, \mathrm{p}=.33)$, whereas in Memo+ the specificity is improved at Visit 2 (Visit $1 \mathrm{M}=1.25, \mathrm{SD}=1.13$; Visit $2 \mathrm{M}=2.81, \mathrm{SD}=1.90, t(16)=4.96, \mathrm{p}<.001$ ) but significantly decreased at Visit 3 (Visit $3 \mathrm{M}=1.63, \mathrm{SD}=1.50, t(14)=-4.28, \mathrm{p}<.001$ ), returning to the baseline level of performance $(t(14)=1.69, \mathrm{p}=.11)$. The Diary group's specificity did not differ between assessments (Visit $1 \mathrm{M}=1.71, \mathrm{SD}=1.21$; Visit $2 \mathrm{M}=1.76$, $\mathrm{SD}=1.56$; Visit $3 \mathrm{M}=1.47, \mathrm{SD}=1.24 ; p=45, \mathrm{p}=.34, \mathrm{p}=.57$, respectively). In short, as hypothesised, there is a clear and maintained benefit of SenseCam review on the accessibility and specificity of autobiographical memories. 


\section{THE COGNITIVE EFFECTS OF WEARABLE CAMERAS ON MEMORY}

\subsubsection{Other cognitive domains}

We present in Table 3 the complete set of results in the neuropsychological assessment measures without baseline group differences at the three time points for the three groups.

\section{INSERT TABLE 3 ABOUT HERE}

\section{Episodic Memory}

Word List (WMS-III) [42]

The word list test yields several measures. For immediate recall, a weak to moderate effect of Group was found, $\mathrm{F}(2,43)=5.47, \mathrm{p}<.001, \eta^{2} \mathrm{p}=.20$, and post-hoc LSD comparisons revealed that the SenseCam group ( $\mathrm{LSD}, \mathrm{p}=.01$ ) and the Memo+ group (LSD, $\mathrm{p}=.01$ ) had a superior performance to the Diary group, but that the Memo+ and SenseCam groups did not differ (LSD, p=.99). An equally weak to moderate effect of Visit was also found, $\mathrm{F}(2,43)=14,67, \mathrm{p}<.001, \mathrm{\eta}^{2} \mathrm{p}=.25$ and LSD pairwise comparisons with Bonferroni adjustment identified lower scores in Visit 2 compared to Visit 1 $(\mathrm{p}<.001)$ but not to Visit $3(\mathrm{p}=.17)$, and higher scores in Visit 3 compared to Visit 1 $(\mathrm{p}<.001)$. A moderate interaction effect was found for Group X Visit, $F(2,43)=23.13$, $\mathrm{p}<.001, \eta_{\mathrm{p}}^{2}=.36$, where the SenseCam group scores increased at Visit 2 remaining at the same level at Visit 3, the Memo+ group scores increase at Visit 2 but decreased at Visit 3 (despite to a level superior to baseline - Visit 1), and the Diary group scores decreased at Visit 2.

Similar results were found for short delay recall, with a weak to moderate main effect of Group, $\mathrm{F}(3,43)=4.53, \mathrm{p}=.01, \mathrm{n}_{\mathrm{p}}^{2}=.17$, with the Memo+ group having an improved performance comparatively to the control group Diary (LSD, $\mathrm{p}<.001$ ), without other significant group differences. No main effect for Visit was found $(\mathrm{p}=.22)$ but a moderate, interaction effect of Group X Visit was found, $\mathrm{F}(3,43)=7.97, \mathrm{p}<.001, \mathrm{\eta}^{2} \mathrm{p}=.27$, indicating that for the SenseCam group the two Visits after the intervention ( 2 and 3 ) held similar scores, both higher than Visit 1 . The Memo+ group scores were only superior to baseline at Visit 2, and the Diary group scores followed an opposite pattern, decreasing at Visit 2.

For the long delay recall scores, a weak to moderate main effect of group was also found, $\mathrm{F}(3,45)=5.50, \mathrm{p}<.001, \eta^{2} \mathrm{p}=.21$, with higher scores for the Memo+ group compared to the Diary group (LSD, $\mathrm{p}<.001)$. A weak to moderate main effect of visit was found, 


\section{THE COGNITIVE EFFECTS OF WEARABLE CAMERAS ON MEMORY}

$\mathrm{F}(3,43)=4.53, \mathrm{p}=.01, \mathrm{\eta}_{\mathrm{p}}^{2}=.18$, and LSD pairwise comparisons indicated that scores increased at Visit 2 compared to Visit $1(\mathrm{p}<.001)$ which was somewhat maintained at Visit 3 ( $\mathrm{p}=.07)$, whose scores did not differ from Visit 1. A weak to moderate interaction effect was also found, $\mathrm{F}(3,43)=3.86, \mathrm{p}<.001, \mathrm{\eta}^{2} \mathrm{p}=.15$, as the SenseCam group scores increased at Visit 2 compared to Visit 1 and were maintained at follow-up, whereas the Memo+ group scores increased at Visit 2, but returned to the Visit 1 level at Visit 3. In the Diary group, despite there being a decrease in the scores across visits, these differences were not statistically significant.

Finally, for the retention rates, an effect with weak to moderate strength of Group was found, $F(3,43)=4.71, p=.01, \eta^{2} p=.18$, and post-hoc Fisher LSD indicate that the Memo+ group had higher scores than the Diary group (LSD, p=.01) without any further differences identified. No effect of Visit was found, $F(3,43)=1.89, p=.16$, but a weak to moderate interaction was found between Group and Visit, $\mathrm{F}(3,43)=4.07, \mathrm{p}<.001, \eta^{2}{ }_{\mathrm{p}}=.16$. The interaction analysed through paired samples t-test indicated that, as for the previous scores, the SenseCam group retention rates increased at Visit 2 and remained superior to baseline at Visit 3, and the Memo+ group scores only increased at Visit 2, approaching Visit 1 levels at Visit 3.

Rivermead Behavioural Memory Test - III, route task (RBMT-III) [43]

For the Route task of the RBMT-III, in the immediate recall, the effect of Group only approached significance, $F(3.43)=2.44, p=.09$. A moderate effect of Visit was found, $\mathrm{F}(3.43)=27.22 ., \mathrm{p}<.001, \eta^{2} \mathrm{p}=.39$, and LSD pairwise comparisons with Bonferroni correction showed that scores increased at Visit 2 compared to Visit 1 (LSD, p<.001), and decreased at Visit 3 compared to Visit 2 (LSD, p<.001). A moderate to strong interaction effect for Group X Visit was found, $F(3,43)=16.61, p<.001, \eta^{2}$ =.44, with SenseCam group scores increased at Visit 2. Despite decreasing at Visit 3, the SenseCam group's scores remained above baseline levels. In the Memo+ group, the scores at Visit 3 were statistically similar to baseline/Visit 1 .

For delayed recall, a weak to moderate effect of Group was found, $F(3,45)=9.68, \mathrm{p}<.001$, $\eta^{2} \mathrm{p}=.19$, where the SenseCam group (LSD, $\mathrm{p}=.02$ ) and the Memo+ group (LSD, $\mathrm{p}=.05$ ) had a superior performance to the Diary group, and these two groups did not differ (LSD, $\mathrm{p}=.71$ ). A main effect with equivalent strength of Visit was found, $F(3,43)=9.68, p<.001$, 
$\eta^{2} \mathrm{p}=.18$, with scores being higher at Visit 2 compared to Visit 1 (LSD, $\mathrm{p}<.001$ ), without significant differences between Visit 2 and Visit 3 (LSD, p=1). A moderate interaction effect was found for Visit X Group, $F(6,41)=12.81, \mathrm{p}<.001, \mathrm{\eta}^{2} \mathrm{p}=.37$. Only the SenseCam group showed significant differences between the baseline assessment (Visit 1) and the Visit 2, and the higher scores at Visit 2 were maintained at Visit 3.

Keys sub-test task (CAMPROMT) [44]

For the CAMPROMT time based prospective memory task, the main effect of group approached significance, $F(3,43)=2.47, p=.09$, but a moderate main effect of Visit was found, $\mathrm{F}(3,43)=29.86, \mathrm{p}<.001, \mathrm{\eta}_{\mathrm{p}}^{2}=.37$, and there was an interaction between Group and Visit, $\mathrm{F}(3,43)=6.61, \mathrm{p}<.001, \eta_{\mathrm{p}}^{2}=.24$, with also moderate strength. The SenseCam group scores increased after the intervention (Visit 2) and remained above baseline at followup (Visit 3), whereas the Diary group scores decreased at follow-up. The Memo+ group scores were not different across visits.

\section{Semantic Memory}

Pyramids and Palm Trees (P \& P) - picture version [45]

For this task, a weak to moderate main effect of Group was found, $F(3,45)=5,60, p<.001$, $\eta^{2} \mathrm{p}=.21$, with the SenseCam (LSD, $\mathrm{p}=.06$ ) and the Memo+ group (LSD, $\mathrm{p}<.001$ ) having a superior performance than the Diary group, without differences between the SenseCam and the Memo+ groups (LSD, p=.15). A moderate effect of Visit was also found, $\mathrm{F}(3,45)=22.90, \mathrm{p}<.001, \mathrm{n}_{\mathrm{p}}^{2}=.35$ with higher performance in Visit 2 compared to Visit 1 $(\mathrm{p}<.001)$ and no significant differences between visits 1 and $3(\mathrm{p}=.54)$. The interaction between Visit and Group was found to be moderate, $F(6,41)=13,77, p<.001, \eta^{2}{ }^{2}=.39$. The SenseCam group scores indicated higher scores both at Visit 2 and Visit 3 compared to Visit 1, but also higher scores were obtained at Visit 2 compared to Visit 3 indicating some loss at follow up. In the Memo+ group, the improvement of the scores at Visit 2 was maintained at Visit 3, compared to baseline. The Diary group scores followed the opposite path, maintaining stable at Visit 2 compared to Visit 1, and decreasing significantly at Visit 3.

Attention and Executive Function

Digit span (DS) task (WMS-III) [42] 


\section{THE COGNITIVE EFFECTS OF WEARABLE CAMERAS ON MEMORY}

This instrument yields results for both forwards and backwards tasks, which we will analyse separately. For the DS forwards, a weak to moderate main effect of Group was found, $F(3,43)=3.72, p=.03, \eta^{2} p=.15$, and Post Hoc LSD indicated that only SenseCam scores were significantly higher than the control group - Diary (LSD, p=.02), without any additional differences between each other pair of groups (Memo+ and SenseCam, LSD, $\mathrm{p}=.39$; Memo+ and Diary, LSD, $\mathrm{p}=.33$ ). A main effect of Visit was not detected but a weak to moderate interaction was found, $F(3,43)=7.10, p<.001, \eta^{2} p=.25$. The SenseCam group scores did not change across Visits, whereas the Memo+ group scores improved at Visit 2 but decreased at Visit 3 to a similar mean score to Visit 1. The Diary group scores decreased after the intervention - Visit 2 compared to baseline, and remained stable at baseline.

For the DS backwards, a moderate main effect of Group was found, $F(2,45)=11.79$, $\mathrm{p}<.001, \eta^{2} \mathrm{p}=.35$, and post-hoc LSD comparisons showed that both SenseCam group $(\mathrm{p}<.001)$ and the Memo+ group $(\mathrm{p}<.001)$ have a higher performance than the Diary group, and these two groups did not differ $(\mathrm{p}=.92)$. A weak main effect for Visit was also found, $\mathrm{F}(2,46)=5.14, \mathrm{p}=.01, \mathrm{\eta}_{\mathrm{p}}^{2}=.11$, with an improved performance in Visit 2 compared to Visit $1(\mathrm{p}=.03)$, but no differences between Visit 3 and Visit $1(\mathrm{p}=.47)$. A moderate interaction between Visit $X$ Group was found, $F(4,44)=9.04, p<.001, \eta^{2} p=.30$. In the SenseCam group, no differences between assessments were found. In the Memo+ group, participants had higher scores in Visit 2 compared to Visit 1, maintained at Visit 3. In the Diary group, there is a decline in the scores at Visit 2 compared to Visit 1 and this decline is accentuated at follow-up - Visit 3.

Verbal fluency test

As explained above, due to differences at baseline in semantic fluency, we only carried the mixed ANOVA analysis for the phonetic fluency task of this test. In this task, the main effect of Group only approached significance, $F(2,45)=3.06, p=.06 . \eta^{2} p=.13$, without being made any further post hoc analyses. A weak main effect of Visit was also found, $\mathrm{F}(3,45)=4.07, \mathrm{p}=.03, \mathrm{\eta}^{2} \mathrm{p}=.08$ and a moderate interaction of Group X Visit, $\mathrm{F}(4,44)=7.93, \mathrm{p}<.001, \eta^{2} \mathrm{p}=.27$. Only the SenseCam group revealed an effect of the intervention, with a higher result at Visit 2 compared Visit 1, which was maintained higher at Visit 3, without statistical differences from Visit 2. No differences across Visits were detected in the Memo+ group. The Diary group, contrary to the SenseCam group, 


\section{THE COGNITIVE EFFECTS OF WEARABLE CAMERAS ON MEMORY}

revealed a pattern of progressive decline in performance, with significantly lower scores at Visit 2 compared to Visit 1, and with accentuated decline at Visit 3 compared to Visit 2.

Digit Symbol-Coding (WAIS-III) [46]

For this instrument, no main effects of Group or Visit, neither interaction effects were found.

\section{Discussion}

The present study aimed to examine the effectiveness of three different memory training interventions to stimulate memory and overall cognition in mild AD patients in a sample of 51 patients. The participants were randomly assigned to one of three groups: one group wore the camera SenseCam daily and took part in sessions to review SenseCam images, another group took part in paper-and-pencil cognitive exercises to practice effective memory strategies, and the control group wrote a personal diary daily and read and shared with the experimenter the diary entries. We tested the neuropsychological performance of these groups before, immediately after and six-months after the end of cognitive training sessions.

We considered the AMT scores as the main outcome for our study, due to the impact on well-being and its place as part of the central episodic memory deficit in AD. Although our focus was on within-subject changes compared to baseline, we can provide a preliminary comparison with healthy older adults using data from previously published studies using the same task. At baseline, for our AD sample we found a mean AMT score of $16.69, \mathrm{SD}=4.51$, (all groups) compared to Moses et al., where the healthy older adults mean was 22.20, $\mathrm{SD}=5.65$ ) [47]. The specificity scores were also somewhat lower than the healthy controls in Moses et al. (in our study the AMT specificity score at baseline was $\mathrm{M}=1.91, \mathrm{SD}=1.11$, and in Moses et al., it was $\mathrm{M}=5.40, \mathrm{SD}=1.83)$. However, in the present study, the participants that wore the SenseCam significantly improved their scores compared to the remaining intervention groups, and their scores remained higher at follow-up (the global score at follow-up was 24.2, which is in keeping with a healthy level of performance according to the means in Moses et al.). The Memo+ group also experienced an improvement in AM scores after training but the effect was not 


\section{THE COGNITIVE EFFECTS OF WEARABLE CAMERAS ON MEMORY}

maintained at follow-up. As expected, the Diary group experienced no effects of the intervention on AM.

These results are, on one hand, in line with previous research with wearable cameras such as SenseCam [1], suggesting that SenseCam pictures act as strong cues of autobiographical memories. However, this result extends such findings, since the AM measure used in this study was a measure of global AM (not related to a particular time point, or the contents of the reviewed images) and included the assessment of specificity. SenseCam use in the present study was effective in stimulating AM performance more generally, and not only to stimulate memory for specific events related to the pictures captured [3]. This generalization effect had been previously found with healthy older adults [5], but this is the first time that this effect has been examined in AD. We propose that this effect is related to the visual nature of the personally relevant images, which can mimic the nature of autobiographical memories, and which directly, and passively, innervates the memory networks in the brain $[48,1]$. That is, during review of the images, memory networks are stimulated during the recognition of the images and the generation of memories associated to the depicted events. However, this stimulates the memory networks more generally, such that, when asked to retrieve autobiographical memories from other time points, they can be more fluently generated, given that they also depend on visual imagery, and the activation of the same autobiographical memory networks. The relation between memory networks and visual imagery is known - and when visual imagery is improved, so is autobiographical memory [49]. Of most relevance, Berry and colleagues [50] examined the activation of neural networks using fMRI in a single case report comparing activations for SenseCam review and re-reading written reports of events. They found that SenseCam review differentially activated regions thought to be responsible for episodic memory (a large series of activations taking in left ventrolateral prefrontal cortex, right frontal pole, bilateral posterior temporal lobe, bilateral parietal cortex, bilateral visual association cortex and left fusiform gyrus). In short, stimulation of autobiographical memory networks merely by watching personal images form the recent past can possibly help stimulate diffuse brain regions which are used to retrieve autobiographical memories, but which are critical for other cognitive tasks (see below). This is an idea in need of further support and it should be tested directly in AD with neuroimaging. 


\section{THE COGNITIVE EFFECTS OF WEARABLE CAMERAS ON MEMORY}

We also aimed to analyse more deeply the effects of this wearable camera on other memory areas (episodic and semantic memory), attention and executive function. While the Memo+ intervention included specific tasks aimed to stimulate attention [33], working memory/executive function [34], verbal episodic memory [36], visual episodic memory [35], prospective memory [37], neither the SenseCam intervention nor the Diary intervention were specifically structured to train any of these areas of cognition. Despite some limitations of our analyses, due to baseline group differences in some of the specific measures of episodic memory, the data analysed suggest that the SenseCam and the Memo+ groups, compared to the Diary group, had improved performance in episodic memory after the intervention. However, a difference was found in the long-term effects of the interventions. While for the episodic memory measures the SenseCam effects were maintained at follow up, in the Memo+ group only the effects in semantic memory scores were maintained at the six-month interval.

The obtained data were less clear for the measures related to executive function. Despite the expected finding concerning the absence of an effect in the measure of attention and processing speed (as it is known that for an attention and processing speed training to be effective it needs to be intensive and last at least fifteen to eighteen subsequent sessions, which is not the case for our study) [51], the remaining measures revealed different patterns of efficacy for each of the intervention groups. An advantage of SenseCam over the other two groups was found for verbal fluency (we only analyzed the phonetic fluency, due to the groups differences at baseline in semantic fluency), where this group had improved performance after the intervention and this increase was maintained at follow up. The Memo+ group showed an advantage in the digit span backwards task after the intervention, and this effect was maintained after six-months. Contrary to these positive effects, the Diary group demonstrated a progressive decrease in performance, compatible with the progressive impairment in this cognitive domain in mild AD.

The effects of SenseCam in other measures than autobiographical memory can be partially explained by the activation of neural networks directly related with AM that would allow its effect to generalize to other cognitive domains connected to these 


\section{THE COGNITIVE EFFECTS OF WEARABLE CAMERAS ON MEMORY}

networks. This could be clarified by having a better understanding of the neural circuits activated by SenseCam images, a priority for future research. However, we cannot rule out the possibility that the generalization effect is due to motivation rather that to a specific cognitive mechanism. In our study on the subjective experience of using SenseCam, Memo+ and a Diary [52], these same patients rate the experience of using SenseCam as being more helpful and allowing them to manage memory difficulties compared to the Diary condition. On the other hand, the fact that the Memo+ condition participants rated their experience of that intervention similarly to the SenseCam condition, suggests that they were motivated and enjoyed that experience, which might explain why both conditions had a positive impact on cognitive performance other than AM. These similar effects between SenseCam and Memo+ might indicate that the SenseCam, which was our "test" intervention in this study, is not necessarily a better alternative to a traditional and intensive memory training programmes, because its effects in cognitive performance of $\mathrm{AD}$ patients are equivalent. However, the passive nature of SenseCam intervention, the pleasantness of using the device and the social nature of reviewing its images (for example: "I really like to see what I was doing these days with my daughter"), coupled with the low burden for caregivers compared to other external memory aids (e.g., a written diary) makes it a practical solution when there are few human resources to provide active cognitive interventions like Memo+ and also an alternative resource for patients who tend to deny their difficulties (in the mild stages, this is common, [32]). Therefore, it is our opinion that the best way to provided more confidence in this device as an efficient alternative to traditional memory training interventions would be usability testing to examine how enjoyable are each tool is to use (such as is done, for example, with online cognitive training platforms, [53]).

Another interesting effect from in this study is related to the maintenance of cognitive effects for both the SenseCam and the Memo+ interventions after six months after the end of the intervention. In accordance with the nature of $\mathrm{AD}$ one should expect that the effects of the interventions should dissipate after this time interval, because of the ongoing neurological deterioration, which is present in the performance pattern of the Diary group. This effect is, then, unusual, but we can highlight some possible explanations for it. One explanation might be the possible practice effects between the three evaluations. The same tests were used at the three assessments, which we consider to be a limitation of this 


\section{THE COGNITIVE EFFECTS OF WEARABLE CAMERAS ON MEMORY}

study. Although this is a possibility, it is also true that the practice effects should have been similar for the three conditions, and the pattern of performance in the Diary condition (showing a deterioration in performance for a variety of measures between Visit 1 and 2). Nevertheless, in order to clarify the effects found in the present study and to completely rule out practice effects, one should try to build, in a future study, an alternative but equivalent set of instruments to be used in these time intervals. Otherwise, we suggest that this effect over 6 months is a consequence of the strength of the stimulation of the neural networks which maintains their activation over longer periods of time. As there is as yet weak evidence of these mechanisms, future studies should aim to examine these effects over shorter periods of time ( 2 weeks, 1 months, 3 months) in order to understand the patterns of stimulation and their strength over time.

In sum, our results add weight to the evidence base of wearable camera use in AD. Researching which mechanisms are responsible for these effects is of greatest scientific importance in the close future in the field. Additionally, another limitation of this study the fact that the experimenter was not blind to the interventions and its effects - means that we consider that the next step is to have a larger patient study that should be a double blind clinical trial. Further limitations include the existence of between group differences at baseline on some measures, and the absence of some instruments to assess more deeply relevant cognitive domains. Another issue is that without a healthy control group, we are not sure of the general benefits of this device. Similarly, without a group who undergoes no training, we are reliant on within-subject comparisons with baseline as the main evidence for the efficacy of SenseCam.

This study represents an important first step being a relatively large group study examining the benefits of SenseCam using standardized measures. The superiority of SenseCam over an intensive memory training programme (Memo+) in memory performance and in some measures of executive function, suggests that such devices can be beneficial for memory stimulation for AD patients in the mild stages of the disease. Additionally, the similar effects of SenseCam and the Memo+ to improve episodic and semantic memory in a way that the gains were maintained in a six-month interval is a proof of both the power of SenseCam pictures as memory enhancers [1] and also the 


\section{THE COGNITIVE EFFECTS OF WEARABLE CAMERAS ON MEMORY}

importance of a multiple-task memory training programmes that help the patient to practice memory strategies that could help them in daily life $[54,55]$. It would be interesting to perform sessions of cognitive training using both types (SenseCam and the Memo+) in order to understand if this complementary application would influence the magnitude of the positive effects found in this study. We do consider that the control group we used for this study is possibly not the most appropriate, as the lack of visual information in the Diary group intervention makes it a less comparable resource of cognitive training relatively to SenseCam and the Memo+ programme. We therefore think that a future study should perhaps include a control group with photographs taken with regular cameras [56] so that we are able to control for the presence of visual data to stimulate cognition.

\section{Conclusions}

Our conclusions need to be cautious given that this work is experimental and full clinical trials are required. However, as we predicted, based on results in healthy older adults and on a handful of studies on small samples of patients, we find a benefit on cognitive performance of using SenseCam in AD. Most importantly, we found improvements in autobiographical memory which were larger than for other forms of memory rehabilitation, and which were sustained after six months. Perhaps most importantly, we found generalized benefits of SenseCam review on autobiographical memory retrieval, on unrelated standardized test of function and not just for the retrieval of the events depicted in the SenseCam images. We propose that this is due to the stimulation of brain regions responsible for autobiographical memory retrieval in the review of the images a hypothesis which will need direct testing, probably with functional neuroimaging in patient groups. Of practical importance, where the benefits of SenseCam were matched or bettered by our Memo+ memory training programme (most notably for many measures on the word list learning task), it must be remembered that review of SenseCam images is a passive activity which yields comparable results to this intensive, neuropsychologistimplemented memory training. We propose that further larger scale studies need to be carried out on the use of wearable cameras in $\mathrm{AD}$, but that this, the largest experiment carried out to date, suggests that this will be a promising avenue for the rehabilitation of memory. 


\section{THE COGNITIVE EFFECTS OF WEARABLE CAMERAS ON MEMORY}

\section{References (in order of appearance)}

1. Silva, A., Pinho, S., Macedo, L. \& Moulin, C (2016). A critical review of the effects of wearable cameras on memory. Neuropsychological Rehabilitation, $6: 1$ 25.

2. Hodges, S., Williams, L., Berry, E., Izadi, S., Srinivasan, J., Butler, A.,...Wood, K. (2006). SenseCam: A retrospective memory aid. Paper presented at the 8th International Conference of Ubiquitous Computing (UbiComp 2006).

3. Berry, E., Kapur, N., Williams, L., Hodges, S., Watson, P., Smyth, G., ... Wood, K. (2007). The use of a wearable camera, SenseCam, as a pictorial diary to improve autobiographical memory in a patient with limbic encephalitis: A preliminary report. Neuropsychological Rehabilitation, 17(4-5), 582-601. doi:10. 1080/09602010601029780Pauly-Takacs et al.,2011

4. Browne, G., Berry, E., Kapur, N., Hodges, S., Smyth, G., Watson, P., \& Wood, K. (2011). SenseCam improves memory for recent events and quality of life in a patient with memory retrieval difficulties. Memory, 19 (7), 713-722. doi:10.1080/09658211.2011.614622

5. Silva, A., Pinho, S., Macedo, L., \& Moulin, C. (2013). Benefits of SenseCam review on neuropsychological test performance. American Journal of Preventive Medicine, 44(3), 302-307. doi:10.1016/j.amepre. 2012.11.005

6. Williams, J. M. G., \& Broadbent, K. (1986). Autobiographical memory in suicide attempters. Journal of Abnormal Psychology, 95, $144-149$.

7. Milton, F., Mulhert, N., Butler, C. R., Smith, A., Benattayallah, A., \& Zeman, A. Z. (2011). An fMRI study of long-term everyday memory using SenseCam. Memory, 19(7), 733-744. doi: 10.1080/09658211.2011.552185

8. St Jacques, P., Conway, M., \& Cabeza, R. (2011). Gender differences in autobiographical memory for everyday events: retrieval elicited by SenseCam images versus verbal cues. Memory, 19(7), 723-732. doi: $10.1080 / 09658211.2010 .516266$

9. Conway, M. (2005). Memory and the self. Journal of Memory and Language, 53, 594-628.

10. Svoboda, E., McKinnon, M. C., \& Levine, B. (2006). The functional neuroanatomy of autobiographical memory: a meta-analysis. Neuropsychologia, 44(12), 2189-2208. 
11. Dalgleish, T., Williams, J. M. G., Golden, A. M. J., Perkins, N., Barrett, L. F., Barnard, P. J., ... \& Watkins, E. (2007). Reduced specificity of autobiographical memory and depression: the role of executive control. Journal of Experimental Psychology: General, 136(1), 23.

12. Greene, J. D., Hodges, J. R., \& Baddeley, A. D. (1995). Autobiographical memory and executive function in early dementia of Alzheimer type. Neuropsychologia, 33(12), 1647-1670.

13. Collette, F., Van der Linden, M., Juillerat, A.C., \& Meulemans, T. (2003). Cognitive-neuropsychological aspects. In R. Mulligan, M. Van der Linden, \& A.C. Juillerat (Eds.), The clinical management of early Alzheimer's disease: A handbook (pp. 35-73). Mahwah, NJ: Lawrence Erlbaum Associates.

14. Backman, L., Small, B., \& Fratiglioni, L., (2001). Stability of the preclinical episodic deficit in Alzheimer's disease. Brain, 124, 96-102

15. Addis, D. R., Tippet, L. J. (2004). Memory of myself: autobiographical memory and identity in Alzheimer's disease. Memory, 12, 56-74.

16. Sitzer, D. I., Twamley, E. W. and Jeste, D. V. (2006), Cognitive training in Alzheimer's disease: a meta-analysis of the literature. Acta Psychiatrica Scandinavica, 114: 75-90. doi:10.1111/j.1600-0447.2006.00789.x

17. Olazarán, J., ET AL., (2010). Nonpharmacological Therapies in Alzheimer's disease: A systematic review of efficacy. Dementia and other Geriatric Cognitive Disorders, 30, 161-178.

18. Kapur, N., Glisky E., Wilson B. (2004). Technological memory aids for people with memory deficits. Neuropsychological Rehabilitation, 14((1/2)), 41-60.

19. Kapur, N, Glisky EL, Wilson BA. (2002). External memory aids and computers in memory rehabilitation. In: Baddeley AD, Kopelman MD, \& Wilson BA (eds.). Handbook of Memory Disorders, Second Edition. Chichester: Wiley.

20. Bourgeois, M., Camp, C., Rose, M., White B., Malone, M., Carr, J., et al. (2003). A comparison of training strategies to enhance use of external aids by persons with dementia. Journal of Communication Disorders, 36(5), 361-378.

21. Robertson, I.H., \& Murre, J.M. (1999). Rehabilitation of brain damage: Brain plasticity and principles of guided recovery. Psychological Bulletin, 125, 544-575;

22. Lee, M., \& Dey, A. (2008). Lifelogging memory appliance for people with episodic memory impairment. Paper presented at the 10th International Conference on Ubiquitous Computing. Ubicomp '08. 
23. Crete-Nishihata, M., Baecker, R., Massimi, M., Ptak, D., Campigotto, R., Kaufman, L., Brickman, A., Turner, G., Steinerman, J., \& Black, S. (2012). Reconstructing the Past: Personal Memory Technologies Are Not Just Personal and Not Just for Memory. Human-Computer Interaction, 27(1-2), 92-123. doi: $10.1080 / 07370024.2012 .656062$

24. Woodberry, E., Browne, G., Hodges, S., Watson, P., Kapur, N., \& Woodberry, K. (2015). The use of a wearable camera improves autobiographical memory in patients with Alzheimer's disease. Memory, 23: 340-349. doi: 10.1080/09658211.2014.886703

25. Behl, P., Edwards, J. D., Kiss, A., Lanctot, K. L., Streiner, D. L., Black, S. E., \& Stuss, D. T. (2014). Treatment effects in multiple cognitive domains in Alzheimer's disease: a two-year cohort study. Alzheimer's Research \& Therapy, 6(4), 48. http://doi.org/10.1186/alzrt280

26. McKhann, G. M., Knopman, D. S., Chertkow, H., Hyman, B. T., Jack, C. R., Kawas, C. H., ... Phelps, C. H. (2011). The diagnosis of dementia due to Alzheimer's disease: Recommendations from the National Institute on AgingAlzheimer's Association workgroups on diagnostic guidelines for Alzheimer's disease.Alzheimer's \& Dementia: The Journal of the Alzheimer's Association,7(3), 263-269. http://doi.org/10.1016/j.jalz.2011.03.005

27. Folstein, M., Folstein, S., \& McHugh, P. (1975) "Mini-mental state”. A practical method for grading the cognitive state of patients for the clinician. Journal of Psychiatry Research, 12, 189-198.

28. Yesavage, j. et al., (1983). Development and validation of a geriatric depression screening scale: a preliminary report. Journal of Psychiatry Research, 17, 37-42.

29. Morris, C. et al. (1993). The consortium to establish a registry for Alzheimer's disease. Part IV. Rates of cognitive change in the longitudinal assessment of probable Alzheimer's disease. Neurolog, 43, 2457-2465.

30. Alves, L., Simões, M. R., \& Martins, C. (2012). The estimation of premorbid intelligence levels among Portuguese speakers: The Irregular Word Reading Test (TeLPI). Archives of Clinical Neuropsychology, 27(1), 58-68.

31. Mioshi, E., Dawson, K., Mitchell, J., Arnold, R., Hodges, J.R., 2006. The Addenbrooke's Cognitive Examination Revised (ACE-R): a brief cognitive test battery for dementia screening. International Journal of Geriatric Psychiatry 21, 1078-1085. 


\section{THE COGNITIVE EFFECTS OF WEARABLE CAMERAS ON MEMORY}

32. Choi, J., \& Twamley, E. W. (2013). Cognitive rehabilitation therapies for Alzheimer's disease: A review of methods to improve treatment engagement and self-efficacy. Neuropsychology Review, 23(1), 48-62. http://doi.org/10.1007/s11065-013-9227-4

33. Sohlberg, M., McLaughlin, K, Pavese, A., Heidrich, A., \& Posner, M. (2000) Evaluation of attention process training and brain injury education in persons with acquired brain injury. Journal of Clinical and Experimental Neuropsychology, 22 (5), 656-676.

34. Netto, T. (2010) [Working memory training in older adults] PhD Thesis. University of São Paulo.

35. Dunn, J., \& Clare, L. (2007) Learning face-name associations in early-stage dementia: Comparing the effects of errorless learning and effortful processing. Neuropsychological Rehabilitation, 17, 735 - 754.

36. Lee, S., Park, C., Jeong, J., Choe, J., Hwang, Y.. Park, C., et al. (2009) Effects of spaced retrieval training on cognitive function in Alzheimer's disease (AD) patients. Archives of Gerontology and Geriatrics, 49, 289-293.

37. Fish, J., Wilson, B., \& Manly, T. (2010). The assessment and rehabilitation of prospective memory problems in people with neurological disorders. A review. Neuropsychological Rehabilitation, 20, 161-178.

38. Serrano, J., Latorre, J, Gatz, M., \& Montanes, J. (2004) Life Review Therapy using autobiographical retrieval practice for older adults with depressive symptomatology. Psychology and Aging, 19, 272-277.

39. Arkin, S. (2001). Alzheimer rehabilitation by students: interventions and outcomes.. In Clare, L., Woods, R.(Eds), Cognitive Rehabilitation in Dementia (pp. 273-317).Sussex: Psychology Press.

40. Zanetti, O., Zanieri, G., Giovanni, G. D., Vreese, L. P. D., Pezzini, A., Metitieri, T., \& Trabucchi,M. (2001). Effectiveness of procedural memory stimulation in mild Alzheimer's disease patients: A controlled study. Neuropsychological Rehabilitation, 11, 263-272.

41. Bourgeois, M. (2007) Memory Books and Other Graphic Cuing Systems, Baltimore, MD, Health Professions Press, Inc.

42. Wechsler D. Wechsler Memory Scale-Third Edition. New York: The Psychological Corporation; 1997. 
43. Wilson B. A., Cockburn J., Baddeley A. D. The Rivermead Behavioural Memory Test. Bury St Edmunds, UK: Thames Valley Test Company; 1985.

44. Wilson B. A., Emslie H., Foley J., Shiel A., Watson P., Hawkins K., et al. The Cambridge Prospective Memory Test. London: Harcourt Assessment; 2005.

45. Howard, D., \& Patterson, K. (1992). Pyramids and Palm Trees: A test of semantic access from pictures and words. Bury St Edmunds, UK: Thames Valley Test Company

46. Wechsler D. Wechsler Adult Intelligence Scale-Third Edition. New York: The Psychological Corporation; 1997.

47. Moses A, Culpin V, Lowe C, McWilliam C. Overgenerality of autobiographical memory in Alzheimer's disease. British Journal of Clinical Psychology. 2004;43:377-386.

48. Loveday, C., \& Conway, M. (2011). Using SenseCam with an amnesic patient: Accessing inaccessible everyday memories. Memory, 19(7), 697-704. doi:10.1080/09658211.2011.61.10803

49. Ernst, A., Botzung, A., Gounot, D., Sellal, F., Blanc, F., De Seze, J., \& Manning, L. (2012). Induced brain plasticity after a facilitation programme for autobiographical memory in multiple sclerosis: a preliminary study. Multiple sclerosis international, 2012.

50. Berry, E., Hampshire, A., Rowe, J., Hodges, S., \& Kapur, N. (2009) The neural basis of effective memory therapy in a patient with limbic encephalitis. Journal of Neurology, Neurosurgery and Psychiatry, BMJ Publishing Group, 80 (11), 12021215.

51. Ball, K., Ross, L. A., Roth, D. L., \& Edwards, J. D. (2013). Speed of Processing Training in the ACTIVE Study: Who Benefits? Journal of Aging and Health, 25(8 0), 65S-84S. http://doi.org/10.1177/0898264312470167

52.

53. Silva, A. R., Pinho, M. S., Macedo, L., Souchay, C., \& Moulin, C., (2016). Mnemonic anosognosia in Alzheimer's disease is caused by a failure to transfer online evaluations of performance: Evidence of memory training programs. Journal of Clinical and Experimental Neuropsychology (epub ahead of print)

54. Cruz, V. T., Pais, J., Bento, V., Mateus, C., Colunas, M., Alves, I., ... Rocha, N. P. (2013). A Rehabilitation Tool Designed for Intensive Web-Based Cognitive 


\section{THE COGNITIVE EFFECTS OF WEARABLE CAMERAS ON MEMORY}

Training: Description and Usability Study. JMIR Research Protocols, 2(2), e59. http://doi.org/10.2196/resprot.2899

55.

57. Silva, A.R., Pinho, M.S., Moulin, C.J., Macedo, L., Caldeira, S., \& Firmino, H. (submitted) It is not only memory: Effects of SenseCam on improving well-being in patients with Mild Alzheimer Disease

58. Bourgeois, M., Dijkstra, K.,m Burgio, L., \& Allen-Burge, R. (2001). Memory aids as an augmentation and alternative communication strategy for nursing home residents with dementia. AAC Augmentative and Alternative Comunication, 17, 196-210. 


\section{THE COGNITIVE EFFECTS OF WEARABLE CAMERAS ON MEMORY}

Figure 1. Study protocol and number of participants in each study phase

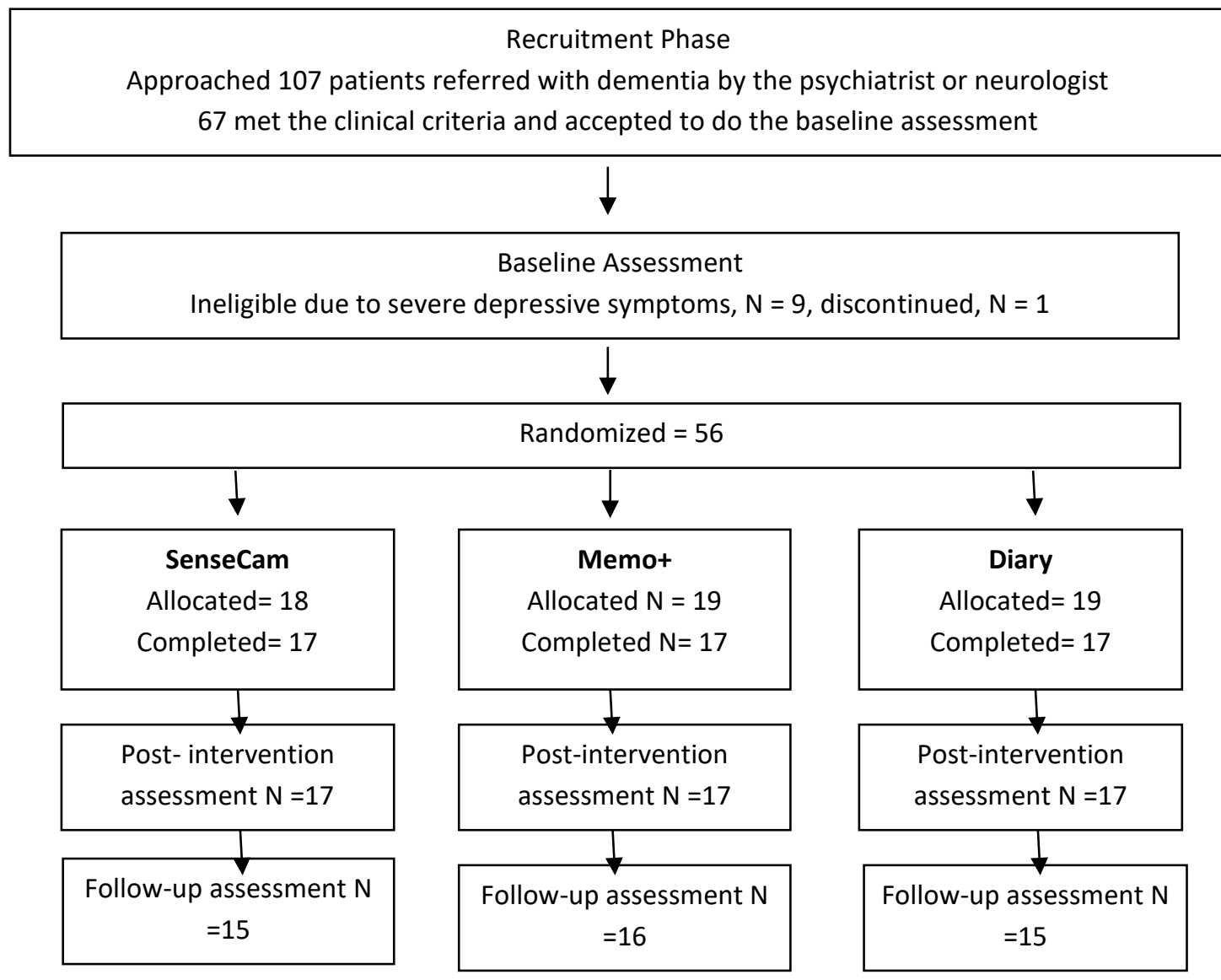


40 ,

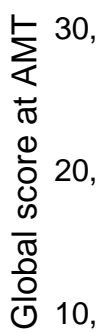
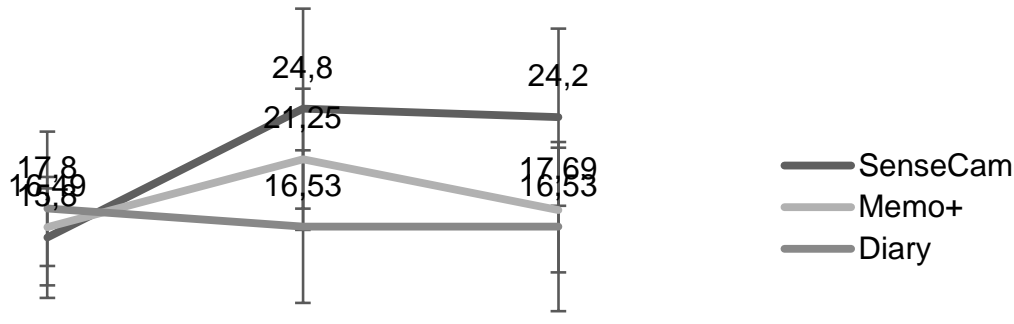

0 ,

Visit 1 (before Visit 2 (one week Visit 3 (6 months intervention) Assessmetert moments after)

Figure 2. Group means of the global score of the Autobiographical Memory Test, across the three assessment visits 
THE COGNITIVE EFFECTS OF WEARABLE CAMERAS ON MEMORY

Table 1. Neuropsychological tests

\begin{tabular}{|c|c|}
\hline Test & Domain assessed \\
\hline Autobiographical Memory Test - AMT [6] & $\begin{array}{l}\text { Autobiographical memory as cued by key } \\
\text { words. This measures the memory for } \\
\text { personal events from across the lifespan. }\end{array}$ \\
\hline Word Lists [42] & Verbal episodic long term memory, \\
\hline $\begin{array}{l}\text { Route task from the Rivermead } \\
\text { Behavioural Memory Test - III [43] }\end{array}$ & $\begin{array}{l}\text { Visuo-spatial episodic long term memory, } \\
\text { and prospective memory }\end{array}$ \\
\hline $\begin{array}{l}\text { Digit Span } \\
\text { [42] }\end{array}$ & $\begin{array}{l}\text { Short-term memory, working } \\
\text { memory/executive function }\end{array}$ \\
\hline $\begin{array}{l}\text { Verbal fluency - phonemic (Portuguese } \\
\text { letter fluency test - P, M, R,) }\end{array}$ & $\begin{array}{l}\text { Lexical access, executive } \\
\text { control/inhibition, processing speed }\end{array}$ \\
\hline $\begin{array}{l}\text { Verbal fluency - semantic (categories: } \\
\text { animals, food, and things we do) }\end{array}$ & $\begin{array}{l}\text { Verbal semantic memory, executive } \\
\text { control/inhibition, processing speed }\end{array}$ \\
\hline $\begin{array}{l}\text { Pyramids \& Palm Trees (P \& P) - pictures } \\
\text { version [45] }\end{array}$ & Semantic memory \\
\hline
\end{tabular}

The keys sub-test task from the Cambridge Time-based prospective memory Prospective Memory Test [44]

Digit Symbol Coding [46]

Speed of processing, attention 
Table 2. Participant characteristics at baseline: neuropsychological assessment $(\mathbf{N}=\mathbf{5 1})$

\begin{tabular}{|c|c|c|c|}
\hline & $\begin{array}{c}\text { Memo+ } \\
N=17 \\
\text { Mean }(S D)\end{array}$ & $\begin{array}{l}\text { SenseCam } \\
\quad N=17 \\
\text { Mean }(S D)\end{array}$ & $\begin{array}{c}\text { Diary (control) } \\
\quad \mathrm{N}=17 \\
\operatorname{Mean}(S D)\end{array}$ \\
\hline Range & $\begin{array}{c}71.71(5.15) \\
63-78\end{array}$ & $\begin{array}{l}75.41(5.26) \\
62-80\end{array}$ & $\begin{array}{l}73.82(5.74) \\
62-79\end{array}$ \\
\hline Years of education & $\begin{array}{c}5.18(3.68) \\
4-15\end{array}$ & $\begin{array}{c}4.76(3.47) \\
3-15\end{array}$ & $\begin{array}{c}6.76(4.63) \\
4-15\end{array}$ \\
\hline $\begin{array}{l}\text { Mini Mental State Examination } \\
\text { (MMSE) } \\
\text { Range }\end{array}$ & $\begin{array}{l}21.53(3.01) \\
16-26\end{array}$ & $\begin{array}{c}21.88(3.33) \\
16-26\end{array}$ & $\begin{array}{c}22.82(1.85) \\
19-26\end{array}$ \\
\hline $\begin{array}{l}\text { Addenbrooke Cognitive } \\
\text { Examination - Revised (ACE-R) }\end{array}$ & $63.18(7.67)$ & $63.12(7.47)$ & $61.06(8.25)$ \\
\hline $\begin{array}{l}\text { Estimated premorbid IQ (TELPI } \\
\text { - Portuguese version of NART) }\end{array}$ & $94.00(13.38)$ & $97.57(12.03)$ & $99.23(15.41)$ \\
\hline Clinical Dementia Rating - CDR & $0.91(0.19)$ & $0.85(0.23)$ & $0.94(0.16)$ \\
\hline Geriatric Depression Scale & $11.88(4.83)$ & $13.35(6.02)$ & 76. (5.92) \\
\hline
\end{tabular}




\section{THE COGNITIVE EFFECTS OF WEARABLE CAMERAS ON MEMORY}

Table 3. Means, standard deviation and $\mathrm{p}$ values for within-group differences in the complete set of standardized cognitive assessment measures

\begin{tabular}{|c|c|c|c|c|c|c|c|c|c|}
\hline & \multicolumn{3}{|c|}{ SenseCam } & \multicolumn{3}{|c|}{ Memo+ } & \multicolumn{3}{|c|}{ Diary } \\
\hline & $\begin{array}{c}1 \\
\mathrm{~N}=17\end{array}$ & $\begin{array}{c}2 \\
\mathrm{~N}=17\end{array}$ & $\begin{array}{c}3 \\
\mathrm{~N}=15\end{array}$ & $\begin{array}{c}1 \\
\mathrm{~N}=17\end{array}$ & $\begin{array}{c}2 \\
\mathrm{~N}=17\end{array}$ & $\begin{array}{c}3 \\
\mathrm{~N}=16\end{array}$ & $\begin{array}{c}1 \\
\mathrm{~N}=17\end{array}$ & $\begin{array}{c}2 \\
\mathrm{~N}=17\end{array}$ & $\begin{array}{c}3 \\
\mathrm{~N}=15\end{array}$ \\
\hline $\begin{array}{l}\text { Word List } \\
\text { immediate (0-36) }\end{array}$ & $\begin{array}{l}16.26 \\
(3.33)\end{array}$ & $\begin{array}{l}\mathbf{2 0 . 4 0}^{\mathrm{a}} \\
(4.84)\end{array}$ & $\begin{array}{l}\mathbf{2 0 . 1 3}^{\mathbf{a}} \\
(4.43)\end{array}$ & $\begin{array}{l}16.87 \\
(5.18)\end{array}$ & $\begin{array}{l}\mathbf{2 1 . 1 8}^{\mathbf{a}} \\
(6.38)\end{array}$ & $\begin{array}{l}\mathbf{1 8 . 7 5} \mathbf{a}^{\mathbf{a}} \\
\mathbf{b}(6.40)\end{array}$ & $\begin{array}{l}15.00 \\
(4.23)\end{array}$ & $\begin{array}{l}\mathbf{1 3 . 3 3}^{\mathrm{a}} \\
(4.19)\end{array}$ & $\begin{array}{l}14.00 \\
(4.23)\end{array}$ \\
\hline $\begin{array}{l}\text { Word List short } \\
\text { delay }(0-12)\end{array}$ & $\begin{array}{l}0.93 \\
(1.09)\end{array}$ & $\begin{array}{l}2.00^{\mathrm{a}} \\
(1.19)\end{array}$ & $\begin{array}{l}1.80^{\mathrm{a}} \\
(1.32)\end{array}$ & $\begin{array}{l}2.06 \\
(2.14)\end{array}$ & $\begin{array}{l}3.00^{\mathrm{a}} \\
(2.16)\end{array}$ & $\begin{array}{l}2.50 \\
(2.25)\end{array}$ & $\begin{array}{l}1.80 \\
(1.24)\end{array}$ & $\begin{array}{l}\mathbf{0 . 6 6}^{\mathrm{a}} \\
(1.04)\end{array}$ & $\begin{array}{l}0.40^{\mathrm{a}} \\
(0.62)\end{array}$ \\
\hline $\begin{array}{l}\text { Word List long } \\
\text { delay }(0-12)\end{array}$ & $\begin{array}{l}0.53 \\
(0.91)\end{array}$ & $\begin{array}{l}\mathbf{1 . 7 3}^{\mathrm{a}} \\
(1.43)\end{array}$ & $\begin{array}{l}\mathbf{1 . 4 7}^{\mathrm{a}} \\
(1.35)\end{array}$ & $\begin{array}{l}1.63 \\
(2.09)\end{array}$ & $\begin{array}{l}\mathbf{2 . 9 3}^{\mathrm{a}} \\
(2.11)\end{array}$ & $\begin{array}{l}2.06 \\
(2.32)\end{array}$ & $\begin{array}{l}1.06 \\
(1.75)\end{array}$ & $\begin{array}{l}0.60 \\
(1.21)\end{array}$ & $\begin{array}{l}0.20 \\
(0.41)\end{array}$ \\
\hline $\begin{array}{l}\text { Word List } \\
\text { retention (\%) (0- } \\
100)\end{array}$ & $\begin{array}{l}12.00 \\
(10.7)\end{array}$ & $\begin{array}{l}27.70^{\mathrm{a}} \\
(22.9)\end{array}$ & $\begin{array}{l}21.95^{\mathrm{a}} \\
(19.5)\end{array}$ & $\begin{array}{l}25.88 \\
(27.0)\end{array}$ & $\begin{array}{l}45.24^{\mathrm{a}} \\
(23.2)\end{array}$ & $\begin{array}{l}33.32 \\
(30.1)\end{array}$ & $\begin{array}{l}25.75 \\
(14.1)\end{array}$ & $\begin{array}{l}10.56 \\
(9.03)\end{array}$ & $\begin{array}{l}6.47 \\
(4.11)\end{array}$ \\
\hline $\begin{array}{l}\text { Route task } \\
\text { immediate }(0-12)\end{array}$ & $\begin{array}{l}8.20 \\
(2.01)\end{array}$ & $\begin{array}{l}\mathbf{1 0 . 7 3}^{\mathrm{a}} \\
(2.71)\end{array}$ & $\begin{array}{l}9.87^{a, b} \\
(2.92)\end{array}$ & $\begin{array}{l}8.63 \\
(1.50)\end{array}$ & $\begin{array}{l}9.88^{a} \\
(1.54)\end{array}$ & $\begin{array}{l}8.63 \\
(1.50)\end{array}$ & $\begin{array}{l}8.40 \\
(0.51)\end{array}$ & $\begin{array}{l}8.07 \\
(0.26)\end{array}$ & $\begin{array}{l}8.16 \\
(0.47)\end{array}$ \\
\hline $\begin{array}{l}\text { Route task } \\
\text { delayed }(0-12)\end{array}$ & $\begin{array}{l}4.67 \\
(1.63)\end{array}$ & $\begin{array}{l}\mathbf{6 . 4 0}^{\mathrm{a}} \\
(1.81)\end{array}$ & $\begin{array}{l}\mathbf{6 . 0 7} \\
(2.25)\end{array}$ & $\begin{array}{l}5.44 \\
(0.77)\end{array}$ & $\begin{array}{l}5.81 \\
(0.41)\end{array}$ & $\begin{array}{l}5.84 \\
(0.72)\end{array}$ & $\begin{array}{l}4.93 \\
(0.46)\end{array}$ & $\begin{array}{l}4.47 \\
(0.84)\end{array}$ & $\begin{array}{l}4.93 \\
(0.46)\end{array}$ \\
\hline $\begin{array}{l}\text { Digit Span } \\
\text { forwards }(0-16)\end{array}$ & $\begin{array}{l}7.00 \\
(1.80)\end{array}$ & $\begin{array}{l}7.47 \\
(2.06)\end{array}$ & $\begin{array}{l}7.20 \\
(2.18)\end{array}$ & $\begin{array}{l}6.06 \\
(0.99)\end{array}$ & $\begin{array}{l}\mathbf{6 . 8 8}^{\mathbf{a}} \\
(1.66)\end{array}$ & $\begin{array}{l}6.63 \\
(1.62)\end{array}$ & $\begin{array}{l}6.47 \\
(1.06)\end{array}$ & $\begin{array}{l}\mathbf{5 . 4 0}^{\mathrm{a}} \\
(1.29)\end{array}$ & $\begin{array}{l}\mathbf{5 . 4 0}^{\mathrm{a}} \\
(1.24)\end{array}$ \\
\hline $\begin{array}{l}\text { Digit Span } \\
\text { backwards (0-16) }\end{array}$ & $\begin{array}{l}4.00 \\
(1.06)\end{array}$ & $\begin{array}{l}4.57 \\
(1.45)\end{array}$ & $\begin{array}{l}4.47 \\
(1.41)\end{array}$ & $\begin{array}{l}3.50 \\
(0.82)\end{array}$ & $\begin{array}{l}\mathbf{4 . 7 5}^{\mathrm{a}} \\
(1.73)\end{array}$ & $\begin{array}{l}\mathbf{4 . 5 6}^{\mathrm{a}} \\
(1.50)\end{array}$ & $\begin{array}{l}3.07 \\
(0.79)\end{array}$ & $\begin{array}{l}\mathbf{2 . 7 3}^{\mathbf{a}, \mathbf{c}} \\
(0.88)\end{array}$ & $\begin{array}{l}\mathbf{2 . 2 0}^{\mathbf{a}, \mathbf{b}} \\
(0.56)\end{array}$ \\
\hline $\begin{array}{l}\text { Verbal Fluency - } \\
\text { phonemic }\end{array}$ & $\begin{array}{l}21.60 \\
(11.5)\end{array}$ & $\begin{array}{l}\mathbf{2 6 . 6 0}^{\mathbf{a}} \\
(8.96)\end{array}$ & $\begin{array}{l}\mathbf{2 6 . 2 7} \\
(9.36)\end{array}$ & $\begin{array}{l}22.25 \\
(15.3)\end{array}$ & $\begin{array}{l}24.56 \\
(14.1)\end{array}$ & $\begin{array}{l}23.69 \\
(13.0)\end{array}$ & $\begin{array}{l}17.93 \\
(8.00)\end{array}$ & $\begin{array}{l}\mathbf{1 6 . 1 3}^{\mathbf{a , c}} \\
(7.18)\end{array}$ & $\begin{array}{l}14.20^{\mathrm{a}} \\
\mathrm{b}(6.06)\end{array}$ \\
\hline $\begin{array}{l}\text { Pyramids \& Palm } \\
\text { Trees 0-52 }\end{array}$ & $\begin{array}{l}39.33 \\
(4.82)\end{array}$ & $\begin{array}{l}\mathbf{4 4 . 3 3}^{\mathbf{a}} \\
(4.03)\end{array}$ & $\begin{array}{l}\mathbf{4 1 . 2 0}^{\mathrm{a}} \\
(5.01)\end{array}$ & $\begin{array}{l}43.00 \\
(4.54)\end{array}$ & $\begin{array}{l}\mathbf{4 5 . 4 4 *} \\
\mathrm{a}(3.50)\end{array}$ & $\begin{array}{l}\mathbf{4 5 . 5 1}^{\mathrm{a}} \\
(3.51)\end{array}$ & $\begin{array}{l}40.27 \\
(5.28)\end{array}$ & $\begin{array}{l}39.93 \\
(5.42)\end{array}$ & $\begin{array}{l}\mathbf{3 7 . 6 3}^{\mathbf{a , c}} \\
(5.32)\end{array}$ \\
\hline $\begin{array}{l}\text { Prospective } \\
\text { memory 0-8 }\end{array}$ & $\begin{array}{l}3.13 \\
(1.36)\end{array}$ & $\begin{array}{l}5.33^{\mathrm{a}, \mathrm{c}} \\
(0.97)\end{array}$ & $\begin{array}{l}4.13^{\mathrm{a}, \mathrm{b}} \\
(1.41)\end{array}$ & $\begin{array}{l}3.13 \\
(1.41)\end{array}$ & $\begin{array}{l}4.06 \\
(1.81)\end{array}$ & $\begin{array}{l}3.38 \\
(1.20)\end{array}$ & $\begin{array}{l}3.47 \\
(1.19)\end{array}$ & $\begin{array}{l}4.00^{\mathrm{c}} \\
(1.07)\end{array}$ & $\begin{array}{l}2.53^{\mathrm{a}, \mathrm{b}} \\
(\mathbf{1 . 1 9 )}\end{array}$ \\
\hline $\begin{array}{l}\text { Symbol-Digit } \\
\text { Coding 0-133 }\end{array}$ & $\begin{array}{l}15.47 \\
(6.68)\end{array}$ & $\begin{array}{l}18.00 \\
(7.64)\end{array}$ & $\begin{array}{l}16.93 \\
(6.42)\end{array}$ & $\begin{array}{l}19.25 \\
(12.22)\end{array}$ & $\begin{array}{l}23.19 \\
(16.02)\end{array}$ & $\begin{array}{l}19.88 \\
(12.27)\end{array}$ & $\begin{array}{l}19.93 \\
(9.08)\end{array}$ & $\begin{array}{l}17.80 \\
(7.36)\end{array}$ & $\begin{array}{l}16.07 \\
(6.53)\end{array}$ \\
\hline
\end{tabular}

Note: Bold numbers indicate within group differences as measured by pairwise comparisons: $\mathrm{a}=$ significantly different $(\mathrm{p}<.05$ corrected) from Visit $1 ; \mathrm{b}=$ significantly different $(\mathrm{p}<.05$ corrected) from Visit 2; $\mathrm{c}=$ significantly different $(\mathrm{p}<.05$ corrected) from Visit 3. 